\title{
Psychosocial factors associated with non-adherence in hemodialysis (hd) patients
}

\author{
Kustimah Usri \\ Department of Clinical Psychology \\ Universitas Padjadjaran \\ Indonesia \\ kustimah@unpad.ac.id
}

\author{
Ahmad Gimmy Prathama Siswadi \\ Department of Clinical Psychology \\ Universitas Padjadjaran \\ Indonesia
}

\author{
Achmad Djunaidi \\ Department of Clinical Psychology \\ Universitas Padjadjaran \\ Indonesia \\ Aulia Iskandarsyah \\ Department of Clinical Psychology \\ Universitas Padjadjaran \\ Indonesia
}

\begin{abstract}
Approximately more than 13,758 people in Indonesia are affected by end-stage renal disease (ESRD); $80 \%$ undergoing hemodialysis. Hemodialysis patients have many problems resulting from the disease itself and treatment process which significantly impacts psychosocial health and quality of life. Non-adherence to treatment is a common problem of great clinical relevance among hemodialysis patients. However, few studies address the psychosocial factors of non-adherence, especially among Indonesia people. This study was aimed to understand the psychosocial factors associated with nonadherence in patients undergoing hemodialysis. Methods: This was a qualitative study, set in the hemodialysis unit of Islamic Hospital in Bandung, total of 11 patients were selected and were invited to semi-structured interviews with open-ended questions. The data obtained were analyzed using thematic analysis based on research of psychosocial factors associated with nonadherence in hemodialysis patients. Result: The analysis of the data led to the extraction of psychosocial factors associated with non-adherence: knowledge, health belief and social support. This research found that acceptance and patient-physician relationship also associated with adherence to treatment.

Keywords- Psychosocial Factor; Non-Adherence;
\end{abstract} Hemodialysis

\section{INTRODUCTION}

The number of End Stage Renal Disease (ESRD) patients in Indonesia is increasing every year. Statistical data shows: in 2011 the number of patient is 15,353 ; rises to 17,193 in 2014 . Most of the patients $(82.4 \%)$ undergo hemodialysis as their treatment choice [1]. In order to succeed in hemodialysis treatment, patients must have good self-management, particularly: adherence to medication prescription, diet and fluid restrictions also complete attendance at hemodialysis session [2].

Adherence is defined as the extent to which a person's behavior corresponds with the agreed recommendations of a healthcare provider in terms of taking medications, following a recommended diet and/or executing lifestyle changes [3]. The prevalence of non-adherence among ESRD patients is quite high. Non-adherence is common issue in patients undergoing hemodialysis. Depending on the definition used, as many as $86 \%$ of the dialysis patients may be considered as non-adherent to one or more aspects of their treatment, but the median is closer to $50 \%$ [4].

Adherence is a multidimensional phenomenon determined by the interplay of five sets of factors: (1) socioeconomic factors, (2) therapy-related factors, (3) patient-related factors, (4) condition-related factors and (5) health care system-related factors [3]. Psychological factor that contributes to adherence will be explained in patient-related factors. Thus, the aim of present study was to identify psychological factors affecting adherence in ESRD patients undergoing hemodialysis.

\section{RESEARCH METHODS}

This study used qualitative approach. Participants included 11 hemodialysis patients selected using purposive sampling method. Inclusion criteria included adult ESRD patient (age greater than 18 years), undergoing hemodialysis for more than 6 months, and speaking bahasa Indonesia fluently. Demographic data of patients i.e. sex, age, marital status, employment, and duration of hemodialysis treatment were recorded (see table 1). Data were collected through face to face semi structured interview for 20-60 minutes. Interview was conducted at Unit Pelayanan Hemodialisa Rumah Sakit in March 2017. Interview was recorded using a digital voice recorder with consent from the participant. Interview questions are related with: 1. Patient's experiences of living with ESRD, 2. Adherence issues relating to living with ESRD, 3. Exploration of psychosocial factors affecting adherence. All patients provided with written consent before the interview recorded. The data were analyzed using thematic analysis. Thematic analysis is a method used to identify, analyze, and report pattern (theme) in data which obtained from qualitative research [5]. 


\section{RESULT}

Socio-demographic data of participants:

\begin{tabular}{|c|c|c|}
\hline No & Demographic Variable & Total \\
\hline \multirow[t]{3}{*}{1} & Sex & \\
\hline & Man & 4 \\
\hline & Woman & 7 \\
\hline \multirow[t]{6}{*}{2} & Age & \\
\hline & $20-30$ & 4 \\
\hline & $31-40$ & 1 \\
\hline & $41-50$ & 3 \\
\hline & $51-60$ & 2 \\
\hline & $>60$ & 1 \\
\hline \multirow[t]{3}{*}{3} & Marital Status & \\
\hline & Married & 6 \\
\hline & Single & 5 \\
\hline \multirow[t]{3}{*}{4} & Employment & \\
\hline & Part-time worker & 6 \\
\hline & Unemployed & 5 \\
\hline \multirow[t]{4}{*}{5} & Duration of Hemodialysis Treatment & \\
\hline & $\leq 12$ months & 2 \\
\hline & $1-5$ years & 5 \\
\hline & $6-10$ years & 4 \\
\hline
\end{tabular}

The following three themes emerged following data analysis:

\section{The importance of knowledge}

All patients report that they did not know what end-stage renal disease (ESRD) and hemodialysis are at the beginning. Patient tried alternative medicine (non-medical) e.g. jamu, herbs, bekam to avoid the hemodialysis which was considered frightening. Patient believed that non-medical treatment was more effortless than medical treatment which takes a long time. Patients undergo the medical treatment after their condition becoming worse. Some patients suffered stroke, heart disease and digestion problems.

At the beginning of disease, I was flustered, searched for alternative medicine because I did not want to undergo the hemodialysis. I tried everything, from using jamu, herbs, and its kind. Consuming all of them in 1 month, my physical condition was drastically declined. My weight decreased, I had no appetite, pale, had no energy at all. When checked, the hemoglobin was only 5 , the renal function got worse, caused by those herbs which made the renal worked harder. (D, 45 years old, 2 years on hemodialysis)

\section{The importance of health belief}

Adherence to treatment also depends on patient's belief and perception. The ways patient perceive the treatment are varied. One of patient's experiences portrays this:

Renal disease feel like the end of everything.. It means just die.. Renal disease means life failure.. A lot of people said that do not undergo hemodialysis, later it will be addictive, the blood will be all suctioned, then inserted again [...] it is confusing and very frightening.. I do not know what to do. (M, 35 years old, 8 months on hemodialysis)

Negative perceptions regarding treatments also lead to skeptical attitudes toward the benefit of treatment, as revealed by one of the following participants:

People said renal disease patients prohibit to take medicine at all.. the renal will be more damage.. the blood get dirtier $[\ldots]$ as for herb, it is allowed since they are more natural and healthier $[\ldots]$ without a needle like in hemodialysis. $(\mathrm{C}$, 55 years old, 1 year on hemodialysis)

\section{The importance of social support}

Support from family, nurse, doctor, and other patients are very important to motivate the adherence of patient while undergo treatments. One of patients share the experience related with this:

The reason why I adhere treatments is mainly because of my parents, I do not want to see them disappointed, sad, my parents has taken care of me, so I do not want to troubled them, so I should do it [...] my parents has tried their best, so I cannot let them down.. Later, I also get a lot of friends, know patients with same disease [...] either from hospital or meeting through social media. (R, 27 years old, 6 years on hemodialysis)

Patients also have unique social relationship with the nurse and the doctor. Some patients even feel very close with the nurse and doctor at hospital, as revealed by one of the following participants:

I have hemodialysis for 7 years at the same hospital [...] I have known the doctors and the nurses very well, and they probably has been wearied with me.. I feel like becoming relatives to doctor $\mathrm{H}$, I do not hesitate to tell about my private life. The nurse is also very kind and very helpful, we often talk.. Not only about the disease but also family [...] If I want to be 'rebellious' and not adhere the treatment, I feel embarrassed since I have known them. (F, 50 years old, 7 years on hemodialysis)

Beside three themes above, there are also important factors which come from patients' experience while they are still in early stage illness. First: most of patients deny their medical conditions. Although the ESRD diagnosis has been very clear and they should undergo hemodialysis, but they feel it was not 
easy to accept the condition. When they got the diagnosis, all patients do not believe it, so they refused to undergo the treatment, as told by one of the following participants:

When I was diagnosed with end-stage renal disease, of course I did not accept it, how can it happened [...] since my activity was travelling as travel journalist. I thought it was common disease, but in fact I need hemodialysis. I cannot accept it because I am still young and still enjoy my life [...] I am a mobile and active person, on the other side I should accept this disease, I cannot believe it. (M, 35 years old, 8 months on hemodialysis)

\section{DISCUSSION}

Limited knowledge of their medical condition and negative perception regarding treatment cause patient hesitate to undergo treatments at hospital. Thus, patient switched to alternative medicine (non-medical) which has not proven able to cure their disease. Patient's knowledge about their disease and treatment are deciding factors to their ESRD treatment adherence [6].

Patient's belief regarding the importance of treatments is predictor whether patient will adhere treatments or not [7]. All participants in this study chose alternative medicine (nonmedical) as knowledge insufficiency about the disease and the suitable medical treatment. They will then adhere the medical treatment after their physical condition declined and showed life risky emergency conditions. It is an apprehensive issue, so education about the disease and its treatments are very important especially for new patients.

ESRD patient's beliefs can also causing treatment nonadherence [8]. Patients think that hemodialysis makes them addicted, has long term negative effects, disturbs their lives, and excruciating. Doctors give them too many medicines, that patients' renal getting worse. In this study, most of patients have the same thought. Then patients do not adhere their hemodialysis sessions, refuse to take medicine, though the medicine prescribed by the doctor mostly in the form of supplement which is important to keep mineral and other substance balanced. Behavioral modification is extremely important to change patients' belief in order to increase their adherence to treatments.

In this study, the family was introduced as one of the most important source of support. The spouse and parents are primary source of support for patient. This finding is similar to the study conducted by Pang et al., (2001) and Asti et al., (2006) [9] [10]. Also Sayers et al. family members should play a greater part in self-care behaviors [11]. Besides, the relationship quality between patients and health-care providers (nurse and doctor) also affecting patient's adherence indirectly

Studies about psychosocial factors affecting ESRD patients in Indonesia are very limited. Results of this study showed that acceptance is a new factor affecting ESRD patient's adherence. When patients accept their conditions, they will be ready to adhere the doctor's recommendation. The adverse psychological condition e.g. depression prevent patient to accept the new role as a sick man and refuses treatments. Further research needs to explore these two factors in order to understand the psychosocial dynamic of ESRD patients, especially in Indonesia.

\section{A. Limitation of Study}

This study used qualitative approach and only utilized interview results as primary data source. Other researchers are suggested to equip the study with questionnaires which proved psychometrically to see which psychosocial factors affecting ESRD patient's adherence to doctor's recommendations. This study involved 11 participants, a limited number for a study's result to be generalized. The suggestion is to add the number of participants, so the study will have statistical power.

\section{B. Implications for Practice}

The findings of study can be used as a basis of designing intervention, aiming to increase the adherence of ESRD patients undergoing hemodialysis. The findings of this study will be useful for all health-care professionals involved in the treatment of ESRD.

\section{REFERENCES}

[1] Indonesian Renal Registry, "7th Report of Indonesian Renal Registry ," 2014.

[2] J. Kammerer, G. Garry, M. Hartigan, and L. Erlich, "Adherence in patients on dialysis is the strategies for success," Nephrology nursing journal, pp. 479-486, 2006.

[3] E Sabate, Adherence to long-term therapies: evidence for action. Geneva: World Health Organization, 2003.

[4] AM. Loghman, "Medication non compliance in patients with chronic disease: issues in dialysis and renal transplantation," Am J Manage Care, pp. 155-171, 2003.

[5] JW. Creswell, Research Design Qualitative, Quantitative, and Mixed Methods Approaches (4th Edition). California: SAGE Publications Inc, 2014.

[6] M. Qobadi, M. Besharat, R. Rostami, and A. Rahiminezhad, "Health literacy and medical adherence in hemodialysis patients: the mediating role of specific knowledge," Thrita, pp. 1-6, 2015.

[7] RM Jones, J Butler, V Thomas, R Peveler, and M Prevett, "Adherence to treatment in patients with epilepsy: Associations with seizure control and illness beliefs," Seizure, pp. 504-508, 2006.

[8] R. Horne, S. Sumber, B. Jubraj, J. Weinman, and S. Frost, "Haemodialysis patients' beliefs about treatment: implications for adherence to medication and fluid-diet restrictions," International Journal of Pharmacy Practice, pp. 169-175, 2001.

[9] S. Pang, W. Ip, and AM Chang, "Psychosocial correlates of fluid compliance among Chinese haemodialysis patients," Journal of Advanced Nursing, pp. 691-698, 2001.

[10] T. Asti, M. Kara, G. Ipek, and B. Erci, "The experience of loneliness, depression, and social support of Turkish patients with continous abluatory peritoneal dialysis and their caregivers," Journal of Clinical Nursing , pp. 490-497, 2006.

[11] SL Sayers, B. Riegel, S. Pawlowski, J. Coyne, and FF Samaha, "Social support and self-care of patients with heart failure," Annals of Behavioral Medicine, pp. 70-79, 2008. 